\title{
Study on Polycarbosilane Fibers Cured by Thermal Process and Electron Beam Irradiation
}

\author{
J. Setiawan \\ Material Science, University of Indonesia; Jl. Salemba Raya No.4 \\ Jakarta 10430, Indonesia \\ Center for Nuclear Fuel Technology-BATAN; PUSPIPTEK GD. 20 \\ Tangerang Selatan 15314, Indonesia \\ Pranjono \\ Center for Nuclear Fuel Technology-BATAN; PUSPIPTEK GD. 20 \\ Tangerang Selatan 15314, Indonesia \\ E-mail: pranjonotaniwiryono@yahoo.com \\ R. Saptaaji \\ Center for Accelerator Science and Technology-BATAN; Jl. Babarsari Mailbox 6101 YKBB \\ Yogyakarta 55281, Indonesia \\ E-mail:rany@batan.go.id \\ S. Poertadji \\ Material Science, University of Indonesia; Jl. Salemba Raya No.4 \\ Jakarta 10430, Indonesia \\ E-mail:spoertadji@gmail.com \\ Sigit \\ Center for Nuclear Fuel Technology-BATAN; PUSPIPTEK GD. 20, \\ Tangerang Selatan 15314, Indonesia \\ E-mail: sigit@batan.go.id
}

\begin{abstract}
A non wovenpolycarbosilane (PCS) fibers was successfully produced by electrospinning and processed by a thermal curing and electron beam curing. PCS solution composition was $1.2 \mathrm{~g} / \mathrm{ml}$ PCS with $30 \% \mathrm{~N}, \mathrm{~N}$-dimethylformamide (DMF) $/ 70 \%$ toluene and the applied voltage at $10 \mathrm{kV}$ in spinning process. The PCS fibers with average diameter $\sim 8 \mu \mathrm{m}$ cured by thermal at $200{ }^{\circ} \mathrm{C}$ with varied time $(1,1.5$ and 2 hour(s)) were compared to thefiber that processed by electron beam curing with varied absorbed doses(approximately 23, 139, 231, 324, 509 and $787 \mathrm{kGy}$ ). The structural changes of PCS fibers after curing process was analyzed by FTIR. The fibers cured by thermal process all shows oxidation curing and fibers cured by electron beam all shows non-oxidation curing. The fibers cured by thermal process with holding time at 1 hour and cured by electron beam with absorbed doses at $231 \mathrm{kGy}$ show the higher crosslinking degree. The fibersthat curing by electron beam are more brittle compared to the fibers that curing by thermal process. The empirical chemical formula for pyrolyzed fiber are $\mathrm{SiO}_{0.49} \mathrm{C}_{0.51}$ for cured at 1 hour, $\mathrm{SiO}_{0.53} \mathrm{C}_{0.47}$ for cured at 1.5 hours and $\mathrm{SiO}_{0.61} \mathrm{C}_{0.39}$ for cured at 2 hours.
\end{abstract}

Keywords: polycarbosilane, PCS fiber, electrospinning, electron beam irradiation.

\section{Introduction}

Contributions Contributions are to be in English. Authors are encouraged to have their contribution checked for grammar. A non woven poly carbosilane(PCS) fibers produced by electrospinning is use for many purpose such as enhanced filler in composite material ${ }^{1}$, acting as filtration membrane ${ }^{2}$, 
nanocensor and enzyme immobilization. ${ }^{3}$ Processing the PCS fiber with curing oxidation, electron beam irradiation $^{4}$ or $\gamma$-ray ${ }^{5}$ will produce infusible fibers to producing a high yield and to improve the properties of the ceramics processing with pyrolysis process. The structure of PCS according to ref. ${ }^{6}$ is

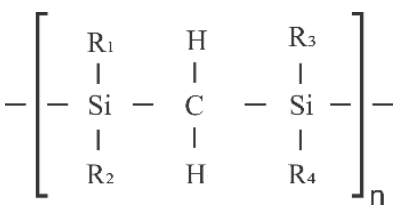

Fig 1. Structure of polycarbosilane. ${ }^{6}$

Where $R_{1}, R_{2}, R_{3}$ and $R_{4}$ respectively are hydrogen, alkyl, aryl, silyl group or a halogen.

Electron beam irradiation on melt spun PCS fibers was done. Melt spun fibers was pre-cured with electron beam irradiation with doses $1.5 \mathrm{MGy}$ and continued to oxidationcuring. ${ }^{4}$ The pre-cured fibers shows the fiber can be easily oxidation cured at fast heating rate without fusion. Differ to PCS fibers without pre-cured, that only with slow heating rate $\left(10{ }^{\circ} \mathrm{C} / \mathrm{h}\right)$ survived, and all the rest fused. ${ }^{4}$ Work on electron beam atmosphere condition onmelt spun PCS fibers was done by compared at doses 0.1-1.4 MGy in oxygen atmosphere and 5-25 MGy in vacuum-He atmosphere. Radical parts resulted on fibers during Electron beam in vacuum-He. These part sreactedeach others and the PCS fiber became crosslinked. ${ }^{7} \mathrm{PCS}$ fibers that irradiated by electron beam at absorbed doses 15 MGy to 35 MGy resulting of $\mathrm{SiC}$ fiber almost constant at $82 \%{ }^{8}$

In this study, we presented on the effect of thermal curing of a non woven PCS fiber produced from electrospinning compared to electron beam curing to the structural changes in PCS fibers. PCS fiber cured by electron beam expected show $\mathrm{Si}-\mathrm{O}, \mathrm{C}-\mathrm{O}$ or $\mathrm{C}=\mathrm{O}$ relative intensity lower. The structural changes of PCS fibers was analyzed by FTIR was observed. Fibers cured by thermal process continued by pyrolysis process in an inert atmosphere for 1 hour at $1000{ }^{\circ} \mathrm{C}$.Thefibers composition after pyrolysis analyzed by SEM and EDS.

\section{Experimental}

Polycarbosilane (PCS) was obtained from NaBond Technology Company. PCS was dissolved by toluene with ratio $1.2 \mathrm{~g} / \mathrm{ml}$, and for processing by electrospinning, N,N-dimethylformamide (DMF) was added to the solution with the ratio of DMF and toluene were 30:70. DMF and toluene were gently stirred for 12 hours with a magnetic stirrer at room temperature and atmospheric pressure.PCS was added slowly to $\mathrm{DMF} /$ toluene solution and continued stirred for 24 hours after the last 12 hours reached.

Electrospinning system from NaBond Technology Company with vertical configuration and using grid configuration collector with grids $5 \mathrm{~mm}$ x $5 \mathrm{~mm}$ was used. The flow rate of solution is $3 \mathrm{ml} / \mathrm{h}$. The fibers wasthermallycuring at $200^{\circ} \mathrm{C}$ with heating rate $2{ }^{\circ} \mathrm{C} / \mathrm{min}$ for $1,1.5$ and 2 hour(s) in oxygen atmosphere and electron beam curing was done in vacuum condition with electron beam irradiator at $300 \mathrm{KeV}$ with 4 mAandabsorbed doses received was approximately 23 , 139, 231, 324, 509 and 787 kGy.FTIR analysis was conducted for both fibers after curing by FTIR Bruker Alpha. Fibers cured by thermal process were pyrolyzed in an inert atmosphere (Ar) at $1000^{\circ} \mathrm{C}$ for 1 hour (heating rate $2{ }^{\circ} \mathrm{C} / \mathrm{min}$ ). The pyrolyzed fibers was observed by SEM JEOL JSM 6510and its compositions analyzed by EDS that attached on SEM.

\section{Results and Discussion}

Fig. 2 and 3 shows FTIR spectra of the PCS fibers that cured by thermal process and electron beam irradiation. There are some significant changes in FTIR spectra in thermal process in wavenumber $1720 \mathrm{~cm}^{-1}, 2100 \mathrm{~cm}^{-1}$ and $2900-2950 \mathrm{~cm}^{-1}$. The PCS fibers cured by electron beam irradiation, the change only at wavenumber 2100 $\mathrm{cm}^{-1}$.Assignments of IR spectrum are tabulated at Table 1 and relative intensity for characteristic peaks for PCS fibers are tabulated at Table 2 . The determined relative intensity for characteristic peaks was according. ${ }^{9}$

Table 1.Wave numbers and assignments of the IR spectrum of PCS. [10]

\begin{tabular}{|l|l|}
\hline Wavenumbers $\left(\mathrm{cm}^{-1}\right)$ & Mode of vibration \\
\hline $850-700$ & $\mathrm{Si}-\mathrm{CH}_{3}$ bending, $\mathrm{Si}-\mathrm{C}$ stretching in $_{\mathrm{SiC}_{4}}$ \\
\hline $950-800$ & $\mathrm{Si}-\mathrm{H}$ bending \\
\hline 1020 & $\mathrm{CH}_{2}$ bending in $\mathrm{Si}-\mathrm{CH}_{2}-\mathrm{Si}$ \\
\hline $1100-1200$ & Si-O stretching in $\mathrm{Si}-\mathrm{O}-\mathrm{Si}$ or $\mathrm{Si}-\mathrm{O}-\mathrm{C}$ \\
\hline 1200 & $\mathrm{C}-\mathrm{O}$ stretching \\
\hline 1250 & Si-CH stretching \\
\hline $1450-1350$ & $\mathrm{H}$ stretching in $\mathrm{CH}, \mathrm{CH}_{2} \& \mathrm{CH}_{3}$ \\
\hline 1720 & $\mathrm{C}=\mathrm{O}$ stretching \\
\hline 2100 & Si-H stretching \\
\hline $2950-2900$ & $\mathrm{C}-\mathrm{H}$ stretching \\
\hline $3700-3200$ & O-H stretching in $\mathrm{Si}-\mathrm{OH}$ \\
\hline
\end{tabular}




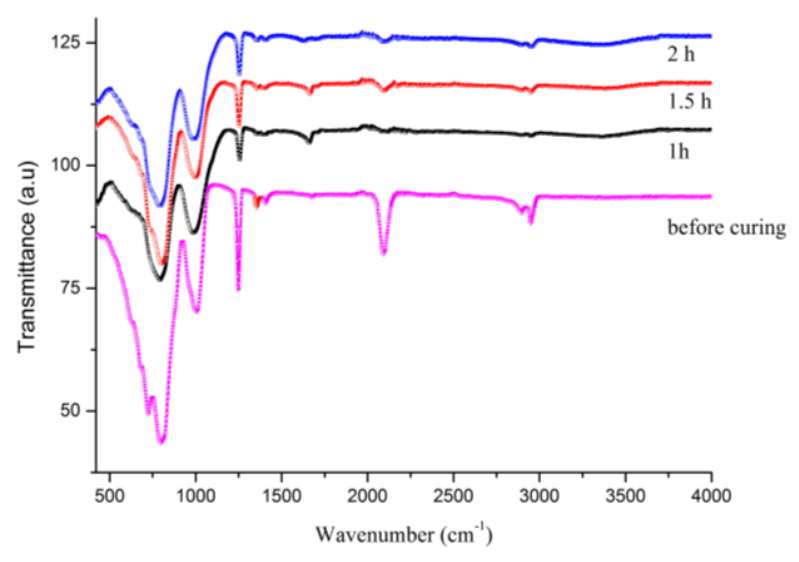

Fig 2.FTIR spectra for thermal curing.

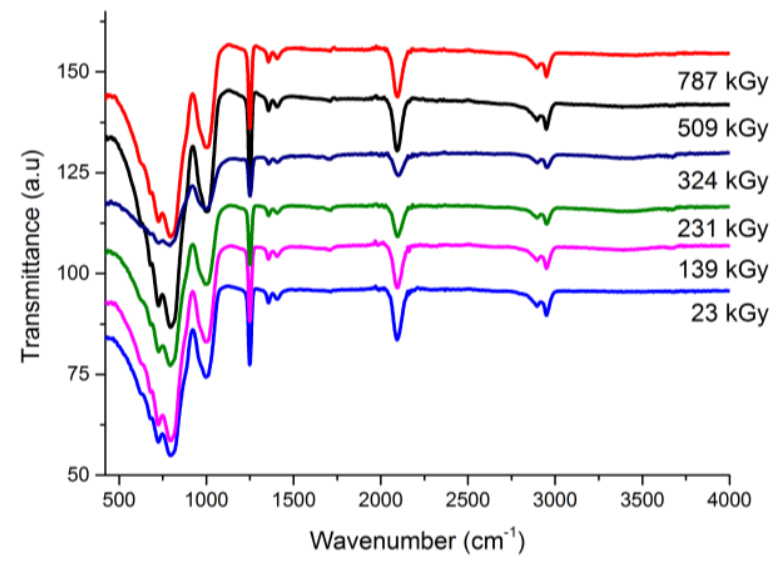

Fig 3. FTIR spectra for electron beam irradiation curing.

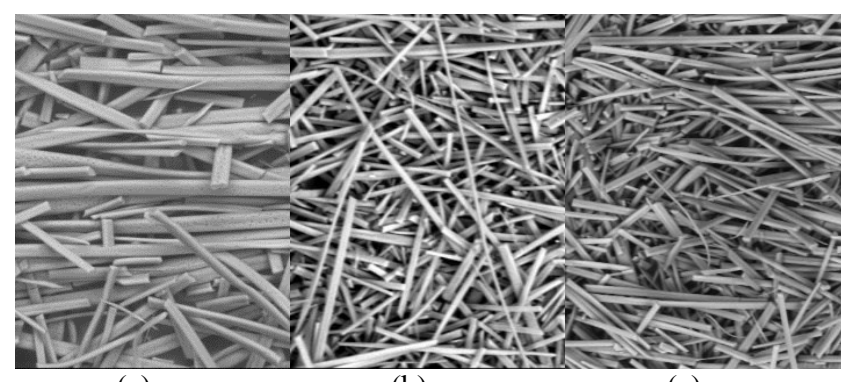

(a)

(c)

Figure 4.SEM image of pyrolyzed fibers for 1 hour at 1000 ${ }^{\circ} \mathrm{C}$ that cured by thermal processfor(a) 1 hour, (b) 1.5 hours and (c) 2 hours.

Table 2.Relative intensity of characteristic peaks for cured fibers.

\begin{tabular}{|c|c|c|c|c|c|c|c|c|c|c|}
\hline \multirow{3}{*}{$\begin{array}{l}\text { Wavenumbers } \\
\quad\left(\mathrm{cm}^{-1}\right)\end{array}$} & \multirow{3}{*}{ Assignation } & \multicolumn{9}{|c|}{ Relative intensity } \\
\hline & & \multicolumn{3}{|c|}{ Thermal } & \multicolumn{6}{|c|}{ Electron beam (kGy) } \\
\hline & & $1 \mathrm{~h}$ & $1.5 \mathrm{~h}$ & $2 \mathrm{~h}$ & 23 & 139 & 231 & 324 & 509 & 787 \\
\hline 1020 & $\begin{array}{l}\mathrm{CH}_{2} \text { bending in } \\
\mathrm{Si}-\mathrm{CH}_{2}-\mathrm{Si}\end{array}$ & 0.04 & 0.05 & 0.03 & 0.24 & 0.18 & 0.06 & 0.27 & 0.14 & 0.17 \\
\hline 1250 & $\mathrm{Si}-\mathrm{CH}_{3}$ stretching & 0.10 & 0.10 & 0.08 & 0.18 & 0.17 & 0.13 & 0.16 & 0.17 & 0.17 \\
\hline 1720 & $\mathrm{C}=\mathrm{O}$ stretching & 0.28 & 0.55 & 1.17 & - & - & - & - & - & - \\
\hline 2100 & Si-H stretching & - & 0.72 & 0.61 & 0.27 & 0.28 & 0.26 & 0.30 & 0.30 & 0.30 \\
\hline $2950-2900$ & C-H stretching & 1 & 1 & 1 & 1 & 1 & 1 & 1 & 1 & 1 \\
\hline
\end{tabular}

Table 2 shows, the PCS Fibers cured by electron beam irradiation there is no peaks detected at wavenumber $1720 \mathrm{~cm}^{-1}$ where assignation by $\mathrm{C}=\mathrm{O}$ stretching. This show the interaction oxygen to the fibers was limited. Differ to the thermal process, where the interaction of oxygen wereoccur during the process. The structure $\mathrm{C}=\mathrm{O}$ was increased as the thermal process time. Thermal process for 1 hour shows the $\mathrm{Si}-\mathrm{H}$ stretching was undetected, this indicated there was high crosslinking degree in the PCS fibers. Absorbed doses at $231 \mathrm{kGy}$ show the lowest intensity for $\mathrm{Si}-\mathrm{H}$ 
stretching, this indicate higher crosslinkingdegree on the PCS fibers. The PCS fibers that cured by electron beam weren't continue to pyrolysis process because the fibers are very brittle than thermal process.

Fig. 4 shows the fibers morphology shows the ribbon-shape type [11]. The fiber compositions were analyzed by EDS and there isincrease in oxygen content. Respectively to the curing time process, empirical chemical formula for the fibers are $\mathrm{SiO}_{0.49} \mathrm{C}_{0.51}[11], \quad \mathrm{SiO}_{0.53} \mathrm{C}_{0.47}$ and $\mathrm{SiO}_{0.61} \mathrm{C}_{0.39}$. These are correlated to oxidation that occur on fibers during the curing.

\section{Summary}

A non woven PCS fibers cured by thermal process and electron beam irradiation was done. An oxidative curing was occur in thermal process, indicated by increaseofrelative intensity at wavenumber $1720 \mathrm{~cm}^{-1}$ in FTIR spectra as curing time. The fibers cured by thermal process show high crosslinking degree when curing time at 1 hour. Non oxidative curing was occur in electron beam irradiation. Absorbed doses of electron beamat $231 \mathrm{kGy}$ show higher crosslinking degree than the others. The fibers cured by electron beam irradiation are more brittle than cured by thermal process. The fibers that cured by thermal process was pyrolysis at $1000^{\circ} \mathrm{C}$ for 1 hour inaninert atmosphere. Empirical chemical formula that derived from EDSforthepyrolyzed fiber are $\mathrm{SiO}_{0.49} \mathrm{C}_{0.51}$ for cured at 1 hour[11], $\quad \mathrm{SiO}_{0.53} \mathrm{C}_{0.47}$ for cured at 1.5 hours and $\mathrm{SiO}_{0.61} \mathrm{C}_{0.39}$ for cured at 2 hours.

\section{Acknowledgements}

The authors are grateful all the staff of Center for Accelerator Science and Technology- BATAN Indonesia for their assistance on this development.

\section{References}

1. Agarwal, P., Mishra, P. K., \& Srivastava, P, Statistical optimization of the electrospinning process for chitosan/polylactide nanofabrication using response surface methodology, J Mater Sci. 47(10) (2012) 42624269.

2. Sigmund, W., Yuh, J., Park, H., Maneeratana, V., Pyrgiotakis, G., Daga, A., Taylor, J.,\& Nino, J. C., Processing and structure relationships in electrospinning of ceramic fiber systems,J. Am. Ceram. Soc. 89(2) (2006) 395-407.
3. Greiner, A., \&Wendorff, J. H., Electrospinning: a fascinating method for the preparation of ultrathin fibers, Angew. Chem. Int. Ed. 46(30) (2007) 5670-5703.

4. Tang, M., Su, Z., Wang, Z., Zhang, L., \&Chen, L., Irradiation pre-curing plus oxidation curing for rapid preparation of silicon carbide fibers, J. Mater Sci 44 (2009) 3905-3908.

5. Narisawa, M., Idesaki, A., Kitano, S., Okamura, K., Sugimoto, M., Seguchi, T., \&Itoh, M., Use of blended precursor of poly(vinylsilane) in polycarbosilane for silicon carbide fiber synthesis with radiation curing, J. Am. Ceram. Soc. 82(4) (1999) 1045-1051.

6. Suwardie H., Kalyon, D. M., \&Kovenklioglu, S., Thermal behaviour and curing kinetics of poly(carbosilane), J. Appl. Polym. Sci., 42 (1991) 10871095.

7. Okamura, K., \&Seguchi, T., Application of radiation curing in the preparation of polycarbosilane-derived $\mathrm{SiC}$ fibers. J. Inorg. Organomet. Polym.,2(1) (1992) 171-179.

8. Idesaki, A., Narisawa, M., Okamura, K., Sugimoto, M., Morita, Y., Seguchi, T., \&Itoh, M., Application of electron beam curing for silicon carbide fiber synthesis from blend polymer of polycarbosilane and polyvinylsilane, Radiat. Phys. Chem., 60 (2001) 483-497.

9. Zheng, C., Zhu, B., Li, X., \& Wang, Y., Study on thermal-curing of polycarbosilane fibers, ActaPolymericaSinica, 2(April 2004) 246-250.

10. Ly, H. Q., Taylor, R., Day, R. J., \&Heatley, F., Conversion of polycarbosilane (PCS) to SiC-based ceramic, Part 1. Characterization of PCS and curing products, J. Mater. Sci., 36 (2001) 4037-4043.

11. Setiawan, J., Pribadi, S., Pranjono, Poertadji, S., \& Sigit, Study on morpology of electrospinning SiOC fibers, In Published. 